\title{
Medical Image of the Week: Kartagener Syndrome
}

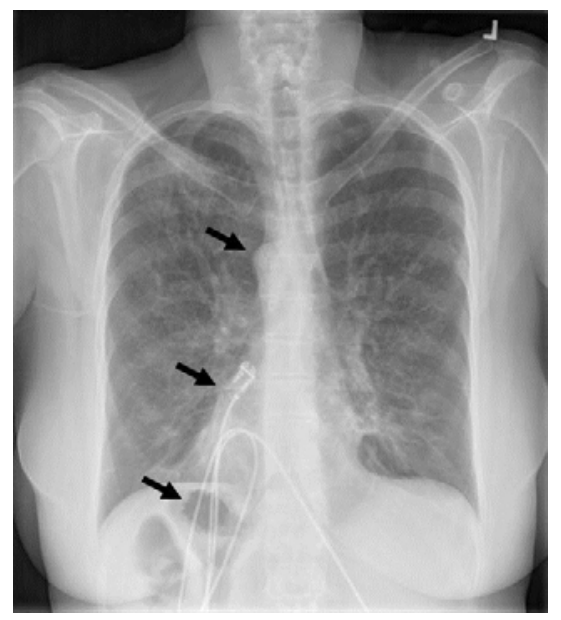

Figure 1. Chest x-ray showing right-sided aortic knob, heart and stomach bubble (arrows).

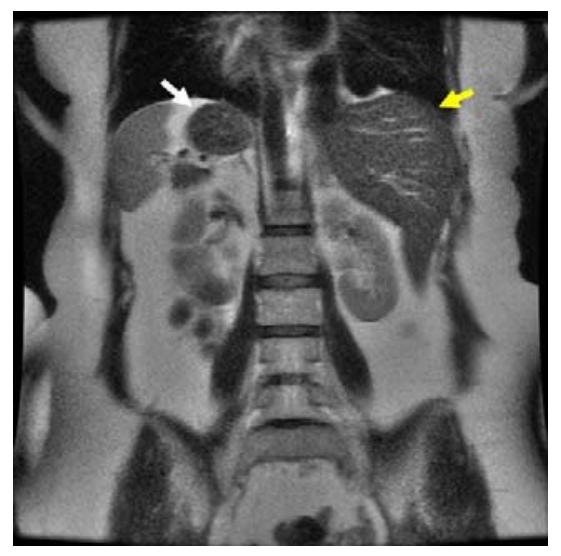

Figure 2. Abdominal CT scan showing right-sided stomach bubble (white arrow) and left-sided liver (yellow arrow).

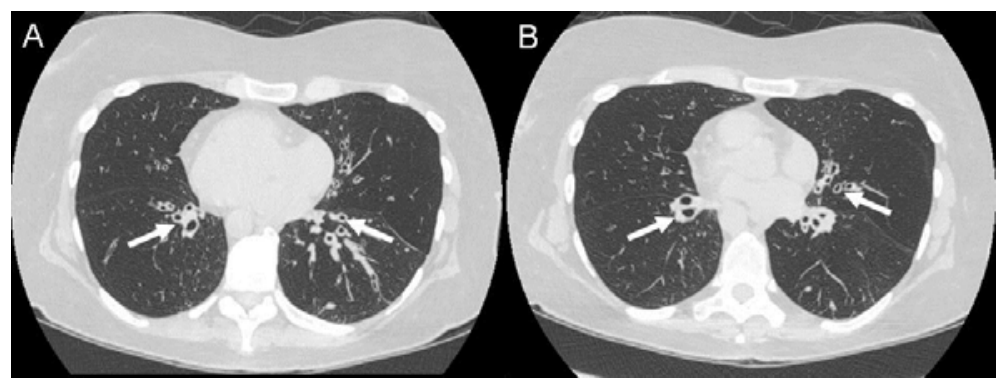

Figure 3. Representative thoracic CT lung windows showing bronchiectasis with bronchi larger than blood vessels with thickened bronchial walls (arrows). 
A 52 year old woman was admitted for dyspnea and fatigue. Kartagener syndrome had been diagnosed at age 3 with situs inversus totalis (Figures 1 and 2). She has bronchiectasis (Figure 3) with chronic Pseudomonas colonization, chronic sinusitis, and nasal polyposis.

Kartagener syndrome is a type of primary cilia dyskinesia or immotile-cilia syndrome. When primary ciliary dyskinesia is combined with situs inversus it is known as Kartagener syndrome (KS) after the Swiss internist who recognized the association of situs inversus, bronchiectasis and sinusitis (1). It is popular in case presentations especially with the chest x-ray or CT scans deliberated presented inverted.

$\mathrm{KS}$ is an autosomal recessive disorder of the ciliary axoneme with incomplete penetrance and extensive heterogeneity (2). The typical ciliary axoneme consists of 2 central microtubules surrounded by 9 microtubular doublets. Patients with primary ciliary dyskinesia exhibit a wide range of defects in ciliary ultrastructure and motility, which ultimately impairs ciliary beating and mucociliary clearance. The most common defect is a reduction in the number of dynein arms, which decreases the ciliary beat frequency.

Treatment is similar to other forms of bronchiectasis and sinusitis. There is no definitive curative therapy.

Nam H. Chan MD, Robert W. Viggiano MD and Lewis J. Wesselius MD Department of Pulmonary Medicine

Mayo Clinic Arizona

Scottsdale, AZ

\section{References}

1. Kartagener M. Zur pathogenese der bronchiectasien. I Mitteilung:bronchiectasien bei situs viscerum inversus. Betr Klin Tuberk. 1933;83:498-501.

2. Bent JP III, Willis EB. Kartagener syndrome. Medscape. Available at: http://emedicine.medscape.com/article/299299-overview (accessed 10/2/13). 